\title{
Oral Health Related Quality of Life with DMFT of Undergraduates and Graduates of Dow University of Health Sciences
}

\author{
Suraiya Hirani ${ }^{1}$ \\ BDS \\ Amynah Tariq ${ }^{2}$ \\ BDS, M.Phil
}

OBJECTIVES: Oral health influences general health; both physically and mentally as it reflects the quality of life. Quality of life pertaining to oral health is acknowledged by WHO as a significant section in Global Oral Health program. Quality of life pertaining to oral health is "the absence of negative impacts of oral conditions on social life and a positive sense of dentofacial self-confidence". To assess oral health \& quality of life in dental undergraduates and graduates of Dow University of Health Sciences using DMFT and OIDP.

METHODOLOGY: The study was conducted for 1 months in July 2016. Samples were collected from undergraduate dental students starting from newly enrolled students to final year and house officers of Dow University of Health Sciences (both campuses: Dow medical college campus and OJHA campus). OIDP survey method was used to measure quality of life and caries index was checked using DMFT index. Analysis were done using SPSS 22.0 software under descriptive analysis; mean comparison and correlation of coefficient at $99 \%$ confidence interval.

RESULTS: Two hundred and forty undergraduates and graduates participated in this study amongst which $73.7 \%$ were females and $26.3 \%$ were males. Only $86.7 \%$ were satisfied from dental treatment they experienced in past two years. According to OIDP scale, sleeping (27.9\%), cleaning (26.6\%) and emotional state were mostly affected, whereas smiling (0.000031), emotional state (0.089) and interacting with people (1.9528E-8) shows statistically significant results in paired T-test. Correlation between DMFT and OIDP show significant results in eating (0.025), speaking $(0.001)$, smiling $(0.002)$, emotional state (0.024) and interacting with people (0.004).

CONCLUSION: This study shows significant impact of oral health on social wellbeing of undergraduates and graduates of Dow University of Health Sciences.

KEY WORDS: QoL, OIDP, OHRQoL, DMFT index.

HOW TO CITE: Hirani S, Tariq A. OHRQoL with DMFT of undergraduates and graduates of dow university of health sciences. J Pak Dent Assoc 2018;27(4):186-89.

DOI: https://doi.org/10.25301/JPDA.274.186

Received: 20 September 2017, Accepted: 14 August 2018

\section{INTRODUCTION}

$\mathrm{Q}$ uality of life (QoL) is manifestation with many meanings. It is associated to individual subject to age, sexual characteristics and cultural situations. It's not a measureable variable but can construct on different perception of each individual. QoL is also reflected by oral health. ${ }^{1}$ Oral health related quality of life (OHRQoL) is "the absence of negative impacts of oral conditions on social life and a positive sense of dentofacial self-confidence". ${ }^{2}$ Oral health has influence on general health both physically as well as mentally. WHO recognized OHRQoL in "Global Oral Health program" (WHO, 2003). It has been generally

1. MSc Trainee, Department of Oral Biology, Dow University of Health Sciences. 2. HOD, Department of Oral Biology, Dow University of Health Sciences.

Corresponding author: “Dr. Suraiya Hirani” < drsuraiyahirani@gmail.com > used in abstract and concrete fields with dental research and medical trials assessing the results of protective and beneficial agendas. Slade, ${ }^{3}$ was the first one who invented the first instrument that measure OHRQoL.

OHRQoL is comparatively a new developing phenomenon. The concept of OHRQOL was first given in the early 1980s. Davis emphasized that except for pain, oral illness does not have any effect on society. It is only interconnected with cosmetic problems; others have reasons that oral disease can be due to recurrent complaints such as headache that were apparent as insignificant problems. ${ }^{4}$

Later, in 1970s; the OHRQOL concept is in progress to grow as more signs are cultivated of the impression of oral disease on society(5). Epidemiological inspection shows trends in OHRQoL, identified definite and natural characteristics that affect OHRQoL and helped in needs and 
health improvement for population-based initiatives. Research has establish that specific groups are at more risk for low OHRQoL. ${ }^{6}$

During few years, a variety of gadgets for assessing QoL comparative to oral health have been intended. Subject to the measures used, QoL linked to oral disorders has been described as difficulties in eating and social collaboration, emotional and psychological function. Oral Impact on Daily Performance (OIDP) has advantage of being used in population survey but measure feelings of individuals. ${ }^{7}$

"World Health Organization's International Classification of Impairments, Disabilities and Handicaps" (ICIDH), has been modified for dentistry by Locker. Impairments means biophysical outcomes of disease. Functional limitation means limitation in body functions. Pain and discomfort is associated with oral disease. Disability and handicap indicates difficulties in performance of daily activities. ${ }^{8}$

With already established association on oral health and QoL most information are based on researches done locally and internationally. There are no such studies regarding relationship between clinical oral health and QoL in our population. Assessing OHRQoL of dental undergraduate and graduate is important as in clinical practice they are responsible for a good oral hygiene habits. Therefore, the objective of this study was to:

1. To assess oral health and quality of life in dental undergraduates and graduates of Dow University of Health Sciences.

2. To study correlation of Caries status using DMFT index and quality of life in Dow University of Health Sciences undergraduates and graduates.

\section{METHODOLOGY}

Study design and study area: A cross-sectional study was conducted at Dow Dental College both campus, OJHA and civil hospital campus. Aims of the study was discussed with head of departments and permissions were taken from all, who participated in this study. Sampling was done according to year of study they were studying for undergraduates and house officers were also included in graduate students sample. Sample size of two hundred and forty was calculated using Power Analysis and Sample Size (PASS) version II with estimated SD of $7.850 .^{9}$ All participants were given validated OIDP survey questionnaire $^{2}$ for quality of life using eight score. OIDP depicts social impact on wellbeing. Participants were asked to score questionnaire accordingly. After that their caries status was checked and recorded using DMFT index by trained post graduate trainee of Dow University of Health
Sciences. Students who had not undergone with any dental treatment or visit over the last two years were excluded from the study. Data was analyzed using SPSS version 22.0. Descriptive analysis was checked with the frequency distribution of study population and affected eight score of OIDP scale. Paired T-test was applied for OIDP score with pain status during dental treatment and satisfaction level of treatment. Correlation of coefficient between OIDP score and DMFT index was checked using 0.001 as statistically significant value.

\section{RESULTS}

Two hundred and forty undergraduates and graduates participated in this study amongst which $73.7 \%$ were females and $26.3 \%$ were males. The mean age of participants was $21.63 \pm 2.19$. Out of two forty (240) one hundred and seventy one (171) were undergraduates and sixty nine (69) were graduates. From a total of $240,86.7 \%$ were satisfied from their dental treatment that they received within last two year (Table 1).

Frequency distribution of affected OIDP illustrates highest percent of participants having difficulty with sleeping with $27.9 \%$ whereas $26.6 \%$ and $26.2 \%$ participants' show difficulties with cleaning and emotional state correspondingly.

Table 1: Frequency distributon of students

\begin{tabular}{|l|l|l|}
\hline VARIABLE & CLASSIFICATION & N(\%) \\
\hline AGE & $21.63 \pm 2.19$ & \\
\hline GENDER & MALE & $63(26.3 \%)$ \\
& FEMALE & $177(73.7 \%)$ \\
\hline STUDY STATUS & STUDENT & $171(71.3 \%)$ \\
& HOUSE OFFICER & $69(28.7 \%)$ \\
\hline YEAR OF STUDY & FIRST YEAR & $48(20.0 \%)$ \\
& SECOND YEAR & $52(21.7 \%)$ \\
& THIRD YEAR & $30(12.5 \%)$ \\
& FINAL YEAR & $41(17.1 \%)$ \\
& HOUSE OFFICER & $69(28.7 \%)$ \\
\hline SMOKING STATUS & YES & $28(11.7 \%)$ \\
& NO & $212(88.3 \%)$ \\
\hline MARITIAL STATUS & SINGLE & $222(92.5 \%)$ \\
& MARRIED & $18(7.5 \%)$ \\
\hline SATISFIED WITH & YES & $208(86.7 \%)$ \\
DENTAL TREATMENT & NO & $32(13.3 \%)$ \\
RECEIVED & & \\
\hline
\end{tabular}

*mean $(S D)$

Table 2: Frequency distribution of eight oidp scores ( $\%$ of affected and mean of oidp score)

\begin{tabular}{|l|l|l|}
\hline VARIABLE & AFFECTED $\%$ & MEAN $\pm S D$ \\
\hline EATING & $23.4 \%$ & $0.51 \pm 1.17$ \\
\hline SPEAKING & $15.4 \%$ & $0.27 \pm 0.77$ \\
\hline CLEANING & $26.6 \%$ & $0.58 \pm 1.17$ \\
\hline SLEEPING & $27.9 \%$ & $0.64 \pm 1.27$ \\
\hline SMILING & $22.8 \%$ & $0.57 \pm 1.30$ \\
\hline EMOTIONAL STATE & $26.2 \%$ & $0.60 \pm 1.22$ \\
\hline INTERACTION WITH PEOPLE & $24.2 \%$ & $0.60 \pm 1.30$ \\
\hline CARRYING MAJOR WORK & $22 \%$ & $0.46 \pm 1.07$ \\
\hline
\end{tabular}


Table 3: Mean comparision of age, gender and year of study with pain status

\begin{tabular}{|l|l|l|l|l|}
\hline VARIABLE & PAINFUL & $\begin{array}{l}\text { NOT PAINFUL } \\
\text { AT ALL* }\end{array}$ & TVALUE & P-VALUE \\
\hline AGE & $20.76 \pm 1.873$ & $21.34 \pm 2.110$ & -2.097 & $\mathbf{0 . 0 3 7}$ \\
\hline GENDER & $1.79 \pm 0.412$ & $1.77 \pm 0.419$ & 0.252 & 0.801 \\
\hline YEAR OF STUDY & $2.36 \pm 1.320$ & $2.99 \pm 1.507$ & -3.179 & $\mathbf{0 . 0 0 2}$ \\
\hline
\end{tabular}

*mean $\pm S D$

Table 4: Mean comparision of age, gender and year of study with satisfaction level of treatment

\begin{tabular}{|l|l|l|l|l|l|}
\hline VARIALBE & $\begin{array}{l}\text { VERY } \\
\text { SATISFIED }\end{array}$ & SATISFIED* & $\begin{array}{l}\text { DIS } \\
\text { SATISFIED }\end{array}$ & FTEST & P-VALUE \\
\hline AGE & $21.08 \pm 2.007$ & $21.36 \pm 2.092$ & $20.04 \pm 1.809$ & 4.237 & 0.015 \\
\hline GENDER & $1.73 \pm 0.449$ & $1.80 \pm 0.399$ & $1.65 \pm 0.483$ & 3.167 & 0.043 \\
\hline YEAR OF STUDY & $2.75 \pm 1.338$ & $3.00 \pm 1.508$ & $2.18 \pm 1.375$ & 6.103 & 0.002 \\
\hline
\end{tabular}

$*$ mean $\pm S D$

Table 5: mean comparision of oidp eight score with pain status

\begin{tabular}{|l|l|l|l|l|}
\hline VARIABLE & PAINFUL* & $\begin{array}{l}\text { NOTPAINFUL } \\
\text { ATALL* }\end{array}$ & $\begin{array}{l}\text { T } \\
\text { VALUE }\end{array}$ & P-VALUE \\
\hline EATING & $0.90 \pm 1.52$ & $0.40 \pm 1.03$ & 2.751 & 0.006 \\
\hline SPEAKING & $0.52 \pm 1.07$ & $0.20 \pm 0.653$ & 2.696 & 0.008 \\
\hline CLEANING & $0.62 \pm 1.25$ & $0.56 \pm 1.15$ & 0.280 & 0.780 \\
\hline SLEEPING & $0.83 \pm 1.45$ & $0.59 \pm 1.22$ & 1.181 & 0.239 \\
\hline SMILING & $0.77 \pm 1.55$ & $0.52 \pm 1.22$ & 1.240 & 0.216 \\
\hline EMOTIONAL STATE & $0.48 \pm 1.01$ & $0.63 \pm 1.27$ & -0.794 & 0.428 \\
\hline $\begin{array}{l}\text { INTERACTION WITH } \\
\text { PEOPLE }\end{array}$ & $0.79 \pm 1.53$ & $0.55 \pm 1.23$ & 1.151 & 0.251 \\
\hline $\begin{array}{l}\text { CARRYING MAJOR } \\
\text { WORK }\end{array}$ & $0.48 \pm 1.11$ & $0.45 \pm 1.07$ & 0.169 & 0.866 \\
\hline
\end{tabular}

$*_{m e a n} \pm S D$

Table 6: Mean comparision of oidp eight score with satisfaction level of treatment

\begin{tabular}{|l|l|l|l|l|l|}
\hline VARIALBE & $\begin{array}{l}\text { VERY } \\
\text { SATISFIED* }\end{array}$ & SATISFIED & $\begin{array}{l}\text { DIS } \\
\text { SATISFIED** }\end{array}$ & $\begin{array}{l}\text { F } \\
\text { TEST }\end{array}$ & P-VALUE \\
\hline EATING & $0.41 \pm 0.88$ & $0.48 \pm 1.19$ & $0.82 \pm 1.33$ & 1.349 & 0.262 \\
\hline SPEAKING & $0.18 \pm 0.50$ & $0.24 \pm 0.66$ & $0.52 \pm 1.32$ & 2.085 & 0.127 \\
\hline CLEANING & $0.62 \pm 1.29$ & $0.51 \pm 1.10$ & $0.88 \pm 1.34$ & 1.427 & 0.242 \\
\hline SLEEPING & $0.72 \pm 1.50$ & $0.60 \pm 1.20$ & $0.76 \pm 1.41$ & 0.287 & 0.751 \\
\hline SMILING & $0.41 \pm 1.16$ & $0.42 \pm 1.04$ & $1.52 \pm 2.07$ & 10.85 & 0.000031 \\
\hline $\begin{array}{l}\text { EMOTIONAL } \\
\text { STATE }\end{array}$ & $0.38 \pm 1.09$ & $0.57 \pm 1.14$ & $1.00 \pm 1.65$ & 2.44 & $\mathbf{0 . 0 8 9}$ \\
\hline $\begin{array}{l}\text { INTERACTION } \\
\text { WITH PEOPLE }\end{array}$ & $0.33 \pm 0.98$ & $0.43 \pm 1.01$ & $1.82 \pm 2.11$ & 19.15 & $1.9528 \mathrm{E}-8$ \\
\hline CARRYING & $0.41 \pm 1.20$ & $0.40 \pm 0.99$ & $0.79 \pm 1.26$ & 1.801 & 0.167 \\
\hline
\end{tabular}

*mean $\pm S D$

Table 7: Correlation for oidp with $\mathrm{dmft}$ index

\begin{tabular}{|c|c|c|c|c|c|c|c|c|}
\hline VARIABLE & DECAYED & & MISSINC & & FILLED & & TOTAL & MFT \\
\hline & CORAELATIN & P.VALLEE & 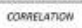 & P.VALLE & cosentation & P.VALUE & COERELATON & P.VALUE \\
\hline EATING & 0.019 & 0.768 & 0.056 & 0.39 & 0.144 & $0.026^{*}$ & 0.145 & $0.025^{*}$ \\
\hline SPEAKING & 0.097 & 0.134 & 0.209 & $0.001 * *$ & 0.033 & 0.614 & 0.217 & $0.001^{*}$ \\
\hline CLEANING & -0.51 & 0.429 & 0.132 & $0.041^{*}$ & 0.012 & 0.856 & 0.079 & 0.221 \\
\hline SLEEPING & -0.007 & 0.915 & 0.105 & 0.103 & -0.029 & 0.652 & 0.053 & 0.413 \\
\hline SMILING & 0.100 & 0.121 & 0.123 & 0.057 & 0.099 & 0.127 & 0.201 & $0.002^{*}$ \\
\hline $\begin{array}{l}\text { EMOTIONAL } \\
\text { STATE }\end{array}$ & 0.120 & -0.046 & 0.067 & 0.300 & 0.063 & 0.330 & 0.146 & $0.024^{* *}$ \\
\hline $\begin{array}{l}\text { INTERACTION } \\
\text { WITH PEOPLE }\end{array}$ & 0.049 & 0.446 & 0.188 & $0.003^{* *}$ & 0.039 & 0.544 & 0.184 & $0.004^{* *}$ \\
\hline $\begin{array}{l}\text { CARAYING } \\
\text { MANOR WORK }\end{array}$ & -0.046 & 0.478 & 0.086 & 0.186 & 0.084 & 0.194 & 0.097 & 0.135 \\
\hline
\end{tabular}

*significant at 0.05 level

**significant at 0.01 level
Detailed percentage distribution of participants having difficulties with affected eight measures of OIDP scale were described in table 2.

The mean comparison of age, gender and year of study with participants having pain during dental treatment was done in which age $(p=0.037)$ and year of study $(p=0.002)$ showed significant results. Age, gender and year of study showed statistically significant results when compared with satisfaction level of treatment (Table 4). Eating ( $\mathrm{p}=0.006$ ) and speaking $(\mathrm{p}=0.008)$ showed significant results when OIDP scale was compared with pain status (Table 5). Detailed mean comparison between eight score of OIDP and satisfaction level of treatment are described in table 6 showing statistically significant results in smiling $(p=0.000031)$, emotional state $(\mathrm{p}=0.089)$ and interaction with people $(\mathrm{p}=1.9528)$.

Oral health and QoL when correlated with DMFT, eating, speaking, smiling, emotional state and interaction with people showed highest value. A detailed correlation was described in table 7 .

\section{DISCUSSION}

Health is defined as a state absence of disease ${ }^{10}$ whereas, QOL is assessment of physical, mental and oral health care. ${ }^{11}$ For evaluating relationship between quality of life with oral health researchers have developed many instruments. SF-36 health form measures relatively the quality of life of the individual whereas Oral Health Impact Profile (OHIP) and Geriatric Oral Health Assessment Index (GOHAI) measures the OHRQoL. OIDP is short and have advantage of not only being used in population survey but measure feeling of the individual. ${ }^{12}$ A study was done on dental students in Malaysia using OIDP scale which showed similar result to this study. ${ }^{13}$

Total 54.3\% participants stated oral functional impact on their daily lives among which female ratio showed highest percentage. Usually key reason for dental visit is pain which could be before the treatment or after treatment, therefore pain during eating and speaking shows significant results in many studies. ${ }^{14}$ Pain is the leading factor to serious problems, but it is also a motivational factor for dental treatment as individual experiencing dental pain has impact on work from their daily lifestyle. ${ }^{15}$

Results of dental students and house officers in 2012 showed difficulty in sleeping while experiencing oral impact ${ }^{16}$, this studies also depicted difficulty in eating which is half that of the study conducted in Thai in $1996 .{ }^{17}$ Functional disability that is, having difficulty in eating and speaking, showed significant results when comparison to study that was conducted in Lahore. ${ }^{4}$ 
Caries index can be measured by many tools among which DMFT is used internationally. It is also used to evaluate manifestation of caries in individual evaluating decayed and filled teeth, therefore correlation among functional disability (eating and speaking), emotional state and social interaction with people and DMFT index were significant statistically. ${ }^{18}$ However esthetics and DMFT was also significant in other study. ${ }^{19}$ However, a negative association between OIDP and DMFT among children was proved in another study. ${ }^{20}$

Complete oral examination with plaque and gingival index and records of the dietary habit of individual may be recorded in further studies as it had greater impact on oral health which can further influence QoL.

\section{CONCLUSION}

DMFT is related to quality of life. This study showed less impact on daily performance in those individuals who had higher number of intact teeth. Oral health has a significant impact on social interaction of dental undergraduates and graduates.

\section{CONFLICT OF INTEREST}

None declared.

\section{REFERNCES}

1. Einarson S, Gerdin EW, Hugoson A. Oral health impact on quality of life in an adult Swedish population. Acta Odontol Scand. 2009;67(2):85-93. https://doi.org/10.1080/00016350802665597

2. Santos CMd, Oliveira BHd, Nadanovsky P, Hilgert JB, Celeste RK, Hugo FN. The Oral Health Impact Profile-14:: a unidimensional scale? Cadernos de Saúde Pública. 2013;29(4):749-57.

https://doi.org/10.1590/S0102-311X2013000800012

3. Slade GD, Spencer AJ. Development and evaluation of the Oral Health Impact Profile. Community dent health. 1994;11(1):3-11.

4. Idris SH, Shujaat NG, Hussain SZ, Chatha R. Oral Health Related Quality Of Life (OHRQoL) in dental undergraduates. Pak Oral Dent J. 2010;30(2)223-228.

5. Bennadi D, Reddy C. Oral health related quality of life. J Int Soci Prevent \& Community Dent.2013;3(1):1-6. https://doi.org/10.4103/2231-0762.115700

6. Sischo L, Broder H. Oral Health-related Quality of Life What, Why, How, and Future Implications. J Dent Res.2011;90(11):1264-70. https://doi.org/10.1177/0022034511399918

7. Åstrøm AN, Okullo I. Validity and reliability of the Oral Impacts on Daily Performance (OIDP) frequency scale: a cross-sectional study of adolescents in Uganda. BMC Oral Health. 2003;3(1):5. https://doi.org/10.1186/1472-6831-3-5
8.Locker D, Matear D, Stephens M, Lawrence H, Payne B. Comparison of the GOHAI and OHIP?14 as measures of the oral health-related quality of life of the elderly. Community Dent Oral Epidemiol. 2001;29(5):373-81.

https://doi.org/10.1034/j.1600-0528.2001.290507.x

9. Isiekwe G, Onigbogi O, Olatosi O, Sofola O. Oral Health quality of life in a Nigerian University undergraduate population. J West African Coll Surg. 2014;4(1):54-74.

10. Brown TM, Cueto M, Fee E. The World Health Organization and the transition from "international" to "global" public health. Am J Pub health. 2006;96(1):62-72.

https://doi.org/10.2105/AJPH.2004.050831

11. Group W. The World Health Organization quality of life assessment (WHOQOL): position paper from the World Health Organization. Soc Sci Med. 1995;41(10):1403-9.

https://doi.org/10.1016/0277-9536(95)00112-K

12. Montero J, López J-F, Vicente M-P, Galindo M-P, Albaladejo A, Bravo M. Comparative validity of the OIDP and OHIP-14 in describing the impact of oral health on quality of life in a cross-sectional study performed in Spanish adults. Med Oral Patol Oral Cir Bucal. 2011;16(6):816-21

https://doi.org/10.4317/medoral.16851

13. Harsh P, Arunima C, Manoj K. Oral health quality-of-life among undergraduate Malaysian dental students. Med J Malaysia. 2012;67(3):299-301.

14. Kaleem M, Jawad M. Association between Socio-demographic features, Oral Hygiene practices and Oral Health utilization services among patients seen at AFID. Pak Oral Dent J. 2016;36(1)110-15.

15. Wilson KE, Opie R. Oral health status and oral impact on daily performance in an adult population with leprosy living in rural Tanzania. J Disability Oral Health. 2009;10(3):124-30.

16. Priya H, Sequeira P, Acharya S, Kumar M. Oral health related quality of life among dental students in a private dental institution in India. J Int Soc Prev Community Dent. 2011;1(2):65-70. https://doi.org/10.4103/2231-0762.97708

17. dulyanon S, Vourapukjaru J, Sheiham A. Oral impacts affecting daily performance in a low dental disease Thai population. Community Dent Oral Epidemiol. 1996;24(6):385-9.

https://doi.org/10.1111/j.1600-0528.1996.tb00884.x

18. Biazevic MGH, Rissotto RR, Michel-Crosato E, Mendes LA, Mendes MOA. Relationship between oral health and its impact on quality of life among adolescents. Braz Oral Res. 2008;22(1): 36-42. https://doi.org/10.1590/S1806-83242008000100007

19. Masalu JR, Åstrøm AN. Social and behavioral correlates of oral quality of life studied among university students in Tanzania. Acta Odontol Scand. 2002;60(6):353-9.

https://doi.org/10.1080/000163502762667388

20. Do LG, Spencer A. Oral health?related quality of life of children by dental caries and fluorosis experience. Journal of public health dentistry. 2007;67(3):132-9.

https://doi.org/10.1111/j.1752-7325.2007.00036.x 